\title{
EL PERDÓN DEL GOBERNANTE EN LAS SOCIEDADES ISLÁMICAS PRE-MODERNAS: SU ESTUDIO A TRAVÉS DEL TA'RIJ IFTITAH AL-ANDALUS DE IBN AL-QUT⿱IYYA
}

\author{
The ruler's mercy in the Pre-modern Islamic societies: its study through Ta'rij iftitah al- \\ Andalus of Ibn al-Qutiyya
}

\author{
Omayra HERRERO \\ CCHS-CSIC \\ E-mail: omayra.herrero@cchs.csic.es
}

Fecha de recepción: $19-01-2010$

Fecha de aceptación: 29-01-2010

\begin{abstract}
RESUMEN: El perdón es un concepto con diversas implicaciones según el contexto religioso y político. En el caso islámico, de Allāh se predica constantemente que es El Clemente, El Misericordioso (al-Raḥmān al-Rahìm). El Corán, la Escritura de los musulmanes, deja claro que Dios castiga, pero también perdona. Así, ¿qué lugar ocupa el perdón dentro de la escala de valores de los musulmanes? Y en el caso de los gobernantes ¿es el perdón un valor moral y religioso, además de político?

El perdón se convierte a menudo en un arma política, en una herramienta de negociación; será pues, esta doble vertiente la que estudiaré a lo largo de esta investigación. El análisis de las fuentes históricas premodernas árabes será uno de los materiales fundamentales de trabajo. En esta ocasión, nos centraremos en el Ta'rīj Iftitāh al-Andalus de Ibn alQūtiyya, donde examinaremos los episodios de perdón que aparecen en él.
\end{abstract}

Palabras Clave: Perdón, gobernante, historiografía, al-Andalus, Ibn al-Qūtịya

ABSTRACT: Forgiveness is a concept with different implications depending on religious and political context. In the case of Islam, about Allah, is constantly preached that He is the Compassionate, the Merciful (al-Rahmān al-Rahim). The Quran, the Scripture of Muslims, makes it clear that God punishes, but also forgives. So what is the place of for- 
giveness within the range of values of the Muslims? And, in the case of the rulers, is forgiveness a moral and religious value, as well as political?

Forgiveness often becomes a political weapon, a tool of negotiation; it is therefore this double perspective that I will study throughout my investigation. The analysis of premodern Arab historical sources will be one of the fundamental materials of work. At this time, we will focus on Ta'rīj Iftitāh al-Andalus of Ibn al-Qūtiyya, where we will examine forgiveness tales taken out of the source, which are a sample of the material with which I work.

Keywords: Forgiveness, Ruler, Historiography, Al-Andalus, Ibn al-Qūṭiyya

\section{INTRODUCCIÓN}

Mi actual proyecto de investigación, encaminado a la realización de mi Tesis doctoral, gira en torno al tema de "El perdón del gobernante. Política y religión en las sociedades islámicas premodernas”. Mi objetivo principal será, en primer lugar, abordar el tratamiento del tema del perdón dentro de la religión islámica, es decir, el lugar que éste ocupa en la escala de valores exigida a los musulmanes, sin olvidar su condición de atributo divino. Y en segundo lugar, y más específicamente, el caso concreto de la clemencia ejercida por el gobernante.

Hoy por hoy, se puede decir que existe una falta de estudios monográficos sobre este tema: tan sólo se ha estudiado de manera transversal en trabajos dedicados a otras cuestiones, en los que salía a la luz la controversia palpable en las actuaciones de los gobernantes en relación con sus actos de compasión o sus castigos. También hay estudios sobre el perdón, pero más generales y de carácter comparativo con el caso cristiano o judío, y casi siempre enfocado desde el punto de vista religioso y no prestando atención al caso concreto de la clemencia real, la compasión del soberano y las causas de su forma de actuar. En este caso, el ámbito de las virtudes religiosas se ve sobrepasado rápidamente, sacando a la luz cuestiones políticas y sociales de un mayor calado y con un interés especial.

\subsection{EL PERDÓN EN EL ISLAM}

Al tratar cualquier tema que roce el ámbito político y religioso en el Islam debemos tener siempre en mente las peculiaridades intrínsecas de esta religión. En el Islam no existe una separación neta entre el representante político y el religioso; no encontramos una institución religiosa separada de las instituciones del Estado - como la Iglesia en el Cristianismo -, la cual se encargue de administrar las cuestiones religiosas. 
Así, veremos que, al hablar de las virtudes morales de los musulmanes, éstas afectan de un modo especial al gobernante de la comunidad, quien tiene que actuar como un verdadero modelo de conducta para sus súbditos. El origen divino de la autoridad hace que la responsabilidad que el soberano tiene sobre sus hombros no sea exclusivamente la de jefe político, sino también la de garante del cumplimiento de la Ley Sagrada (šarì ‘a), así como de la correcta conducta espiritual de los individuos que están bajo su mando.

La conducta modélica del soberano, sus virtudes personales, políticas y religiosas constituyen el tema central de un género literario como son los "Espejos de Príncipes", género muy cultivado en la literatura musulmana de toda época. Forman parte de lo que en árabe se ha denominado adab, que engloba un tipo de obras destinadas principalmente al cultivo del espíritu, al conocimiento de las buenas artes y maneras. En estas obras se pretende definir, a través de diversos relatos ejemplarizantes, el modelo ideal del gobernante que debe regir un estado islámico.

Obras como el Sirâŷal-Mulūk de al-Ṭurțūšî1 o las Nașihāt al-Mulūk de al-Gazāli ${ }^{2}$ nos sirven como ejemplo de este tipo de literatura en la que sus autores intentan contribuir con sus enseñanzas a la capacitación política de sus soberanos para la adquisición y el mantenimiento del poder ${ }^{3}$.

En lo referente al tratamiento del perdón en este tipo de obras, éste suele ocupar un lugar bastante importante en la clasificación de las cualidades propias de los gobernantes. Dice al-Ṭurțūš̄ (m. 520/1129) que "De las cualidades a que nos referimos (aquellas que representan para el soberano lo mismo que la corona, el manto, la compostura exterior y el buen porte), la más perfecta de todas y la que sirve de fundamento a las demás es la clemencia“4.

Sin duda, la clemencia y el perdón en el gobernante son unas de las virtudes más aplaudidas dentro de la escala moral del autor, no sólo como virtud que demuestra la bondad del gobernante sino también como garantía para la consecución del perdón divino el día del Juicio Final. Tal día, el gobernante será juzgado tanto por sus pecados como por los de sus súbditos y, por ello, su salvación estará condicionada por su actuación durante su gobierno ${ }^{5}$.

En cierto modo, el tema del perdón en estas obras estará ligado a la justicia y a la equidad que el soberano debe garantizar al juzgar los delitos cometidos contra alguno de sus súbditos. Cuando el gobernante aplique la ley musulmana ha de ser justo y perdonar a aquellos a los que se ha acusado injustamente. Se insistirá, en muchas ocasiones, en el beneficio que este modo de actuar conlleva para el Estado, pues cuando el gobernante es justo y actúa rectamente, sirve de ejemplo para los vasallos y establece así la justicia y la rectitud entre estos. La justicia aparece así, como deber del soberano, como labor indisociable de su tarea de gobernar y garantizar el buen funciona- 
miento del Estado. Cuando el gobernante aplica la justicia, los súbditos saben a qué atenerse; pero cuando el gobernante perdona, está por encima de la justicia: "Sin cesar otorgas el perdón, y la libertad que concedes a quien delinquió, es ligadura que a ti los une, hasta el punto que a quienes indultas, desean estar a tu lado, aun a costa de grillos y cadenas"6.

\section{EL PERDÓN DEL GOBERNANTE EN LAS FUENTES HISTÓRICAS}

El tratamiento del perdón en las crónicas históricas será diferente al modo en que éste era abordado en los "Espejos de Príncipes". Aquí habremos de extraer el tratamiento de las virtudes exigidas a los gobernantes del relato de la actuación del soberano en distintas situaciones, donde se trata de poner de manifiesto sus bondades. Sin duda, el enfoque religioso de los hechos estará muy presente en las páginas de estas crónicas dadas las exigencias de una sociedad musulmana como era la andalusí. Asimismo, debemos tener en cuenta la inclinación personal del cronista y el contexto en que nace cada obra. De este modo, al estudiar el perdón en estas fuentes, habremos de extraer los relatos en los que se adviertan casos de clemencia o de castigo, para después analizar el modo en que éstos están elaborados, su enfoque particular, tratando de reconstruir la realidad histórica y social que subyacía bajo los acontecimientos narrados.

\subsection{UN CASO PRÁCTICO: EL TA'RIJ IFTITĀH AL-ANDALUS DE IBN AL-QŪTTIYYA}

En esta ocasión, el Ta'rìj Iftitāh al-Andalus, de Ibn al-Qūtiyya nos servirá como modelo para observar el análisis del tratamiento del perdón y el castigo en las fuentes históricas premodernas árabes.

\subsubsection{EL AUTOR Y SU OBRA}

Abū Bakr Muhammad b. 'Umar b. 'Abd al-'Azīz b. Ibrāhīm b. İsà b. Muzāhīm, conocido como "Ibn al-Qūtiyya”, nació en Córdoba, dónde también murió en el año 367/977. Era descendiente, por línea materna, de una familia sevillana de origen visigodo, como manifiesta su laqab (sobrenombre) "Ibn al-Qūtiyya", "hijo de la Goda", en referencia a su tatarabuela Sara "la Goda", hija de Olmundo y nieta del rey visigodo, Witiza.

Ibn al-Qūtiyya se formó en Córdoba y Sevilla, destacó en el estudio de la filología, aunque cultivó varias ramas del saber, alcanzando también una importante fama como ulema y cronista. Pero, sin duda, hoy es conocido por su importante crónica Ta'rīj Iftitāh al-Andalus (Crónica de la conquista de 
Al-Andalus $)^{7}$, de la que sólo se conserva un manuscrito en la Biblioteca Nacional de París.

Ibn al-Qūtiyya recoge en su obra los hechos acaecidos en al-Andalus, desde la conquista de la Península en el año 92/711, hasta la subida al trono de 'Abd al-Raḥmān III (299/912). La relación de clientela de la familia del autor con los gobernantes Omeyas - quienes en su día influyeron en el casamiento de Sara "la Goda" con un musulmán -, así como su puesto de alfaquí en Córdoba, hacen que éste muestre una clara actitud pro-Omeya en su obra.

Por otro lado, se observa un tratamiento de los hechos con una clara distinción entre los buenos creyentes, que cumplen con sus obligaciones y respetan a los demás musulmanes, y los malos creyentes, que transgreden las normas de la religión y sólo buscan su interés por encima del de la Comunidad musulmana. Así, la actitud de Dios será muy distinta respecto a cada uno de ellos, premiando a los virtuosos al tiempo que los malos musulmanes son castigados y condenados al sufrimiento eterno en el Infierno.

El gobernante, evidentemente, se verá condicionado por estas exigencias, de tal manera que el soberano que cumple con sus deberes y que trata a sus vasallos con justicia y bondad, logrará el orden y la prolongación de su reinado; sin embargo, aquel que es injusto e intolerante con sus súbditos, perderá rápidamente su poder y será condenado a largos sufrimientos e indignos finales.

Ahora bien, veremos como estos conceptos religiosos de bondad o maldad estarán tratados en la obra, en buena medida, en relación con el servicio a los Omeyas, de tal modo que aquel que cumple con su obediencia a los Omeyas - representantes de la Autoridad Divina en la Tierra - estará cumpliendo a su vez con la obediencia a Dios y, por tanto, estará siendo un buen creyente, con las consecuencias que esto conlleva, y viceversa. Veremos, pues, un planteamiento de los hechos por parte de Ibn al-Qūtiyya, a primera vista religioso, pero con un objetivo político muy claro, articulando el desarrollo de los hechos en función del servicio o no a los gobernantes omeyas.

\subsubsection{El PERDÓN EN EL TA'RİJ IFTITĀH AL-ANDALUS}

La clemencia del gobernante está planteada en la obra desde el punto de vista del compromiso existente entre el soberano y algunos de sus súbditos, de tal modo que su comportamiento benevolente será consecuencia de los actos de respeto y de cumplimiento de su juramento de lealtad o, por el contrario, encontrarán el castigo de su señor cuando muestren su rebeldía. Con todo esto, se intentará presentar a un gobernante justo, que se comporta 
según lo esperado y que aplica en la Tierra la justicia que Dios aplicará en su día en el Juicio Final.

Sin embargo, el análisis detallado de los acontecimientos nos mostrará cómo, en ocasiones, las conductas no son las esperadas. Como veremos al analizar los ejemplos extraídos de la crónica, la postura pro-Omeya de Ibn al-Qūtiyya será determinante en diversas ocasiones, cuando nos ofrezca una versión "edulcorada" de los hechos o cuando trate de justificar ciertas conductas violentas de los gobernantes.

\section{EJEMPLOS DE PERDÓN: TIPOLOGÍA Y CONTEXTO}

Como venimos advirtiendo, en las crónicas históricas se aborda el tema del perdón como parte del cumplimiento de los compromisos establecidos entre los individuos. En este sentido, será fundamental conocer el funcionamiento de la institución islámica del $a m \bar{a} n /$ "protección", como un pacto entre los individuos y el gobernante en el que ambas partes se comprometen a respetarse mutuamente, siempre y cuando no se viole el acuerdo.

Debemos diferenciar entre dos tipos de amān: el amān de conquista, más común en los primeros momentos de la ocupación musulmana de alAndalus, y el amān del rebelde, más presente durante la época de los gobernadores, cuando los pactos de obediencia y sumisión al poder por parte de los individuos estaban algo más establecidos.

La mayoría de los ejemplos que nos ofrece la crónica de Ibn al-Qūtiyya están relacionados con las consecuencias de la rebeldía. El gobernante no siempre procederá de un modo indulgente, sino que, cuando un individuo muestre una rebeldía manifiesta y no se arrepienta ${ }^{8}$, ni las más sólidas influencias lograrán salvarlo de su castigo. Así lo vemos en el relato de la sublevación en Torrox (Elvira) de 'Ubayd Allāh b. 'Abd al- Azīz, hermano de Hāšim b. 'Abd al- 'Azīz, famoso visir durante el gobierno de Muhammad I, que logró alcanzar una enorme influencia y un importante papel político durante este periodo9 ${ }^{9}$. Dice Ibn al-Qūtiyya que Muḥammad I envió contra el rebelde a su ministro Muhammad b. Umayya con orden de que matara a todos los sublevados. El ministro, al llegar allí, escribió al Emir pidiéndole no matar al hermano de Hāšim. El Emir respondió mandando a uno de sus eunucos para que matara al rebelde él mismo y le trajera su cabeza. Cuando Hāšim se enteró de la muerte de su hermano, enfadado dijo: "Hombre, y no be sido digno, a pesar de mi celo en aconsejarle sinceramente y de haberlo reconocido como patrono, de que perdonara por mi conmiseración las faltas de mi hermano! i Ah, vive Dios!; no he de servirle ya jamás con tanta lealtad"10. Pero el Emir se abstuvo de responderle. 
Parece ser que la pasividad mostrada por el ministro ante las fechorías llevadas a cabo por su hermano no ayudó a que su influencia en la corte cordobesa actuara como medio para ganarse el perdón del soberano ${ }^{11}$.

Por otro lado, vemos como en la crónica de Ibn al-Qūtiyya, el perdón aparece utilizado en buena medida como un simple instrumento político, de tal modo que los soberanos establecen con sus súbditos pactos de protección a cambio de lealtad, con el fin de obtener una mayor influencia y control sobre ellos y evitando así, revueltas y sublevaciones contra su poder. La indulgencia se convierte pues, en un instrumento de negociación muy eficaz para el gobernante. En esta negociación, en muchas ocasiones, actuarán como parte fundamental para el éxito los consejeros. Comprobaremos que la figura del consejero es, en muchos casos, crucial para el buen hacer del soberano, quien, normalmente, tenderá a solicitar la opinión de aquellos a quien tiene en su entorno sobre el modo de actuar para resolver los casos conflictivos, como son las revueltas de los súbditos o el trato de los prisioneros. A estos consejeros se les presenta procurando que el gobernante cumpla con sus obligaciones, para que se garantice el perdón de Dios el día del Juicio Final.

Un ejemplo de esto lo tenemos en el siguiente relato referente a la revuelta del muladí 'Umar b. Hafsūn en Rayya (Málaga), en la segunda mitad del s. III/IX. Tras haber logrado una gran victoria sobre Muhammad b. Abī 'Abda, general de las tropas del Emir 'Abd Allāh contra Ibn Hafsūn, éste, ese mismo día y a pesar de la negativa del general de la caballería de Ibrāhīm b. Haŷŷâŷ, señor de Sevilla y su aliado, lo volvió a atacar y cayó derrotado. De este modo, cuando llegó la noticia a Córdoba, el Emir 'Abd Allāh, quien tenía como rehenes a un sobrino de Ibn Hafsūn y a un hijo de Ibn Haŷŷây, llamado 'Abd al-Raḥmān, mandó que los sacaran y les cortaran la cabeza. Así, se ejecutó al primero pero, al ir a matar al segundo, Badr, mawla/cliente del Emir, le aconsejó que lo dejase vivo para así lograr que se rompiera la alianza que tenían los rebeldes y así, Ibn Haŷŷâŷ volvería a la obediencia al Emir. Tras varias peticiones de consejo, el Emir aceptó el plan de Badr y "no sólo soltó al prisionero, sino que también le expidió y entregó letras credenciales como gobernador de Sevilla y a su hermano Muhammad se las expidió como gobernador de Carmona”. Así, lograron disolver la alianza entre ambos y que Ibn Haŷȳâŷ volviera a someterse al Emir. En cuanto a Badr, fue nombrado ministro del Emir y parte del consejo de los alfaquíes ${ }^{12}$.

Por otro lado, habremos de prestar atención al estudio de la benevolencia y el castigo en relación con las élites del gobernante, lo que nos permitirá ver unas implicaciones específicas para estos personajes, dada su especial relación y su cercanía a los círculos de poder. No hay duda de que esta situación se convierte en un privilegio en muchas ocasiones para aquel que goza de tal estatus; pero también conlleva un enorme riesgo, dada la exposición de estos personajes por su labor en la corte. 
Ibn al-Qūtiyya, en relación con este tema, nos cuenta que el Emir Hišām I, al ocupar el trono, envió un emisario a Algeciras para que hiciera venir al astrólogo al-Ḍabbī, con el fin de que éste le diera su previsión respecto al porvenir de su reinado. El astrólogo, habiendo pronosticado que el reinado de Hišām sería muy corto, intentó abstenerse de responder a su petición. En un primer momento, el Emir le dispensó, pero al enterarse de sus razones, volvió a llamarlo y le dijo: "Ciertamente, si yo te lo pido, ipardiea!, no es porque imagine que sea verdad lo que tú digas, sino que lo hago sólo por el placer de oírlo; de manera que si me dices cosas que puedan causarme disgusto, con seguridad te perdonaré, gratificaré, regalaré vestidos y retribuiré porque me manifiestes lo que ba de darme placer». Y le dijo al-Dabbī: «Pues... de seis a siete (años)». Hišām, tras oírlo, le regaló un traje de honor, lo gratificó y le autorizó para volver a su país. Por su parte, a partir de entonces, se entregó al servicio de Dios y a la vida retirada ${ }^{13}$.

A pesar de ganarse el perdón del Emir en esta ocasión, el riesgo de estar tan cerca del poder y de tener acceso a informaciones privilegiadas, unido a la poca discreción del astrólogo, no le salvó de la condena a muerte que le impuso Muhammad I, con quien la relación empezó a enfriarse tras publicar al-Dabbī cierta información privada del Emir. De este modo, más adelante, sería acusado de practicar la brujería, dada su afición a la magia, lo que le llevó a la muerte ${ }^{14}$.

Este ejemplo nos muestra a un soberano clemente, que no perdona buscando un beneficio, sino que lo hace como mero acto de benevolencia y generosidad, es decir, como puesta en marcha de esa virtud que ha de caracterizar a todo buen gobernante. Cuando estamos ante estos casos, veremos cómo esta clemencia será una muestra del poder del soberano, quien, teniendo la potestad de castigar determinada acción, decide perdonar.

En algunos casos, cuando existen lazos de parentela entre los implicados en el conflicto, el perdón es mucho más rápido. Lo vemos así en el caso de Muṭarrif, hijo del Emir 'Abd Allāh, quien, queriéndose hacer con el poder de su padre, no dudó en usar todos los medios posibles para eliminar a quienes podían impedírselo. Así, mató a su hermano Muhammad, primogénito del Emir 'Abd Allāh y a quien éste había elegido como heredero del trono. Antes, había intentado convencer a su padre de la intención que tenía su hermano mayor de sublevarse contra él, hasta tal punto que 'Abd Allāh llegó a encarcelar a Muhammad. Sin embargo, ante la falta de pruebas contra su hijo, el Emir decidió ponerlo en libertad, pero su celoso hermano se adelantó, entró en la prisión y apuñaló a su hermano.

Después, mató al ministro y secretario de 'Abd Allāh, 'Abd al-Malik b. 'Abd Allāh b. Umayya b. Yazīd, para eliminar a un fuerte defensor del Emir y, después, fue haciéndose con el apoyo de los sevillanos, en contra de su padre. Éste, enterado de los planes de su hijo, hizo lo posible por impe- 
dírselo. Incluso lo amenazó de muerte al enterarse de que había matado a Umayya, diciéndole: "Te he tolerado el que mataras a tu hermano Muhammad, porque al fin y al cabo era desobediente y rebelde; pero voto a Dios, si tú te atreves a hacer alguna novedad con respecto a Ibn Umayya, ten por seguro que te mato entonces" "I5.

Sin embargo, Muțarrif continuó en su empeño, hasta que, viendo que era imposible llevar a cabo su objetivo, "escribió a su padre, pidiéndole perdón, que al momento le fue concedido"'.

Esta historia contiene un trasfondo bastante más interesante de lo aparente, pero habremos de ir por partes. Parece que estamos ante una "ligera" variación de los hechos llevada a cabo por el cronista, con el fin de mostrarnos a un 'Abd Allāh comprensivo, calmado y compasivo. Sin embargo, si nos acercamos a la Historia de Lévi-Provençal, veremos que éste nos dice que, el Emir, furioso por el proceder de su hijo, "tuvo un acceso de furor, y si bien vacilaba algo en hacerlo ejecutar, los alfaquies, movidos por el influyente jurisconsulto Ibn Lubāba le decidieron a ello. Al-Muțarrif se defendió durante tres días en su palacio de Córdoba contra los soldados encargados de detenerlo. Llevado al cabo a presencia de su padre, el 2 de noviembre de 895 (10 ramadān 283), 'Abd Allāh ordenó que fuese inmediatamente decapitado y enterrado bajo un mirto de su jardín, en el sitio mismo donde la víctima tenía costumbre de instalarse para hacer sus libaciones" $"$.

Esta actuación sin duda difiere en gran medida de la versión ofrecida por Ibn al-Qūtiyya. Además, nos sorprende que nos presente una imagen tan suavizada de los hechos, teniendo en cuenta que este Muhammad a quien asesinó Muṭarrif, era el padre del futuro Emir ${ }^{\circ} \mathrm{Abd}$ al-Raḥmān, quien estaba en el poder en el momento en que escribe Ibn al-Qūtiyya.

Este intento de presentarnos a un 'Abd Allāh más compasivo, a pesar de suavizar también así la imagen de Mutarrif, se compensará con unas palabras que añade algunas líneas más adelante, escribiendo que los ministros del reino habían decidido matar a Muṭarrif "porque era conocidamente heterodoxo o hereje", a lo que añade: "Dios lo castigó [a Muțarrif] por haber sido el asesino de su bermano, que sin duda alguna era mejor y mucho más sincero en creencias religiosas que él'18.

Por último, será interesante ver el tratamiento de la clemencia del gobernante ante un hecho de gran calado en la sociedad andalusí como fue la Revuelta del Arrabal. Esta revuelta fue un acontecimiento crucial en el transcurso de los acontecimientos durante el gobierno de al-Hakam I, así como un hecho con un fondo político y social que es digno de explorar. Al subir al trono, al-Hakam heredó un ambiente realmente tenso en la sociedad andalusí de la época, aumentado por las continuas revueltas organizadas por los beréberes, los muladíes y los árabes, disconformes con su mandato. AlHakam decidió organizar un fuerte sistema de espionaje, con gran número de soldados que vigilaban las puertas del palacio cordobés y que estaban dis- 
puestos a sofocar cualquier intento de rebelión. Mientras, al otro lado del Guadalquivir, se había formado un arrabal muy poblado, tanto por gente muy pobre, la plebe cordobesa y los artesanos o comerciantes muladíes o cristianos, como por miembros de la aristocracia árabe, que se habían instalado allí por la cercanía a la mezquita mayor y al palacio de los emires. Este ambiente tan heterogéneo pronto resultaría ser un nido de revueltas contra la actitud impulsiva e injusta del soberano, oposición que también contaría con un apoyo desde el interior de la ciudad, de tal modo que en todas las clases sociales de Córdoba se notaba una corriente de descontento con el soberano.

Todo este ambiente de tensión, revueltas y enfrentamientos encontró su punto álgido cuando un guardia del Emir mató a un espadero por su tardanza en entregarle una espada que le había mandado bruñir. La gente, ante tal abuso, explotó en una revuelta generalizada en todo el Arrabal, de manera que el Emir, cuando volvió a Córdoba - se encontraba de caza - y vio el desorden que reinaba en la ciudad, no dudo en reprimir por la fuerza semejante situación. Durante tres días, continuó la matanza, hasta que al-Hakam fue instado por sus consejeros a dejarlo, aceptando muy a su pesar.

Con semejante desarrollo de los hechos y viendo la actitud del Emir respecto a los sublevados, entenderemos el proceder totalmente implacable de al-Hakam con los rebeldes del Arrabal que fueron detenidos. Ahora bien, también encontraremos casos en los que se nos presenta a un alHakam compasivo y clemente.

Un relato de este tipo lo tenemos en el caso de la rebelión encabezado

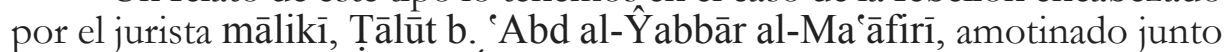
a otros tantos en el Arrabal. Éste, cuando fue derrotado, huyó y se escondió en casa de un judío durante un año. Como era amigo de Abū 1-Bassām alWazīr, ministro de al-Hakam, cuando se apaciguó el enfrentamiento, éste le contó que el Emir ya no le andaba buscando, por lo que Tạāut se fue con él. Sin embargo, el ministro lo delató ante el Emir y fue presentado ante él. Cuando al-Hakam le preguntó las razones de su rebeldía, habiéndose siempre mostrado respetuoso con él, aquel le contestó: «No encuentro abora en mi favor mejor frase que decir que eso es la pura verdad. Dios me ha mandado odiarte y por tanto ningún provecho has sacado de todo lo que conmigo hiciste». Entonces al-Hakam volvió la consideración hacia Dios y dijo al cabo de un rato: «He mandado jvoto a Dios! Por tiy no ha habido en la tierra castigo que no se me haya representado para ver con cuál castigarte; pero te hago saber que aquel por cuya consideración tú me odias me impulsa a perdonarte. Vete con Dios, seguro; no dejaré jvoto a Dios! de hacerte bien, continuando en la consideración en que antes te tenía, mientras viva, si Dios quiere. jOjalá lo que sucedió no bubiera sucedido!» ${ }^{19}$. 
Esta conducta de al-Hakam nos resulta llamativa. Tras la persecución sistemática contra los rebeldes del Arrabal y la crucifixión pública de los condenados, no podemos entender cómo es posible que, presentándosele cara a cara uno de los rebeldes huidos, lo perdone de este modo. Ahora bien, sabemos que este Ṭâlūt era uno de los juristas más ilustres de Córdoba, junto a Yahyà $b$. Yahyà. Por otro lado, esta revuelta coincide con un momento muy concreto en la ascensión en el poder del colectivo de los alfaquíes. Éstos odiaban al Emir porque se negaba a compartir con ellos el poder, ignorando la influencia que éstos habían alcanzado y, por tanto, su obligación a contar con ellos en el ejercicio del poder. Así, su animadversión hacia el Emir parece que podía haberse contagiado poco a poco entre la plebe, unido sin duda a las medidas fiscales abusivas del Emir y al descontento generalizado hacia al-Hakam del que ya hemos hablado.

Por otro lado, vemos que, cuando se marchó Țālūt de su presencia, el Emir recriminó duramente a su ministro por haberlo traicionado, mientras, como dice «un judio ha sabido respetar en él sus altas cualidades de religión y ciencia, aventurándose a si propio, a su mujer, sus bienes y sus propios hijos, todo a un tiempo, ¿y tú - dice al ministro - quieres meterme (otra vez) en aquello de que yo estoy arrepentido? $\rangle^{20}$. Este episodio logra poner de manifiesto la ruindad de este personaje, quien no dudó en denunciar a su amigo ante la posibilidad de ganarse la felicitación del Emir por llevar ante él a uno de los rebeldes huidos. Sin embargo, podemos ver como al-Hakam considera despreciable esta actuación y lo destituye de su cargo, cayendo en desgracia a partir de entonces sus herederos, mientras que Ṭâlūt fue honrado y respetado por el Emir hasta su muerte.

En definitiva, Ibn al-Qūtiyya nos presenta a un al-Hakam arrepentido, calmado, contrapunto del Emir violento y déspota que sofocó la revuelta del Arrabal con la espada ${ }^{21}$. Posiblemente, todo esto no sea más que una estrategia del cronista cordobés de apaciguar la visión negativa que se pueda extraer de la narración de las hazañas del Emir. Por ello, trata de mostrarnos como la represión del Arrabal tuvo su causa justificada y que, después de todo lo ocurrido, al-Hakam se arrepintió del daño que había provocado al tratar de controlar las insurgencias y por eso, perdonó a aquellos rebeldes que volvieron a su obediencia.

\section{CONCLUSIONES}

Como he comentado al inicio, este trabajo está en curso y mucho es lo que queda por hacer y por analizar. Por ello, todavía es difícil sacar conclusiones de peso de la poca información con la que cuento hasta el momento. Sin embargo, me aventuraré a poner sobre 
la mesa algunas cuestiones que se me plantean al enfrentarme a este tipo de relatos.

Sin duda, el peso de la religión en sociedades musulmanas como lo fue la andalusí debió condicionar en gran medida la actuación de los dirigentes de cada momento, así como la del resto de las elites que se movían a su alrededor en la Corte. Entre la plebe, la religión era también un ente que cubría todos los aspectos de la vida de la gente. Por tanto, las crónicas que se redactaban en aquella época y en aquel contexto, conscientes de las exigencias de esta situación particular y, por qué no, por convicción propia en algunos casos, trataban de hacer llegar unos relatos de los acontecimientos que encajasen en el marco en el que veían la luz. Así, vemos como estas crónicas tienen un tinte religioso muy marcado y justifican al lector la actuación de determinados personajes, tratando de integrar sus actos dentro del comportamiento exigido al creyente musulmán.

Sin embargo, el análisis más pausado de los hechos y los personajes que los protagonizan, el conocimiento de los lazos que unen a unos y otros y del contexto político y social en el que se mueven, parece empeñarse en poner de manifiesto una realidad que se aleja poco a poco de estos requerimientos religiosos. Los gobernantes cuando perdonan, perdonan por algo más que por instituirse como modelos de gobernantes clementes. Quizá, buscan ser vistos así, pero quizá, no tengan otra alternativa... La negociación de la que venimos hablando a lo largo de este trabajo, los pactos de lealtad entre el gobernante y sus súbditos para apaciguar sus rebeldías parecen ser las causas que subyacen bajo gran parte de los casos aquí tratados. Así, extraemos una ecuación muy simple: La obediencia es al perdón, como la rebeldía es al castigo.

Con el tiempo, el estudio del resto de las fuentes históricas árabes de la época nos permitirá matizar todo esto y sacará a la luz la validez de esta suposición. Pero hasta el momento, parece que en buena parte, la clemencia de los gobernantes es un modo de ganarse la vuelta a la obediencia de los súbditos insurrectos; y el castigo se aplicará sin piedad cuando la sedición de los súbditos amenace la permanencia en el poder del gobernante de turno, será un castigo a la negativa a arrepentirse, a volver al redil de la obediencia. Ahora bien, como dijo Napoleón Bonaparte,

"Si la obediencia es el resultado del instinto de las muchedumbres, el motin es el de su reflexión" 


\section{NOTAS}

${ }^{1}$ Al-Ṭurțūšì, Sirāŷy al-Mulūk, ed. Ŷa'afar al-Bayātī, Reino Unido, 1990; Lámpara de Príncipes, trad. M. Alarcón, Madrid, 1930, 2 vols.

${ }^{2}$ Al-Gazālī, Nasihāt al-Mulūk, ed. M. A. Damay, Beirut, 1987; trad. al inglés de F. R. C. Bagley, Oxford University Press, Londres, 1971.

${ }^{3}$ O. Guerrero Orozco, "Los espejos de príncipe musulmanes. Un programa de capacitación administrativa de Alta Jerarquía”, Revista Tlamati, 4, 1982, pp. 5-13.

${ }^{4}$ Al-Țurtūšī, 1930, I, 303.

${ }^{5}$ Al-Ṭurțūšī, 1930, I, 308.

${ }^{6}$ Al-Ṭurțūšìi, 1930, I, 310.

${ }^{7}$ Ibn al-Qūtiyya, Historia de la conquista de España de Abenalcotía el cordobés, ed. y trad. J. Ribera, Madrid, 1926 (IQ).

${ }^{8}$ Sobre la doctrina de la rebelión, véase D. Serrano, "Doctrina legal sobre la rebelión en juristas andalusíes", El cuerpo derrotado: cómo trataban musulmanes y cristianos a los enemigos vencidos (Peninsula Ibérica, ss. VIII-XIII), CSIC, Madrid, 2008, pp. 257-282.

${ }^{9}$ Este famoso visir será el antepasado de la familia conocida como los Banū Hāšim 'Abd al-'Aziz. Sus hijos estuvieron a punto de ser crucificados por el Emir al-Mundir, pero a su muerte, el Emir 'Abd Allāh los absolvió. V. Fierro, "Familias en el Ta'rīj iftitāh al-Andalus de Ibn al-Qūtiyya", EOBA, IV, CSIC, Granada, 1990, pp. 41-70.

${ }^{10}$ IQ, 1926: 83.

${ }^{11}$ M. Jiménez Puertas, Linajes de poder en la Loja islámica. De los Banū Jālid a los Alatares, Granada, 2009, 107-108, siguiendo a al-Jušanī, Kitāb al-qudāt bi-Qurțbba, trad. J. Ribera.

${ }^{12}$ IQ, 1926: 96-97.

${ }^{13}$ IQ, 1926: 32-33.

${ }^{14}$ Sobre al-Ḍabbī y la información que de éste nos ofrece el Muqtabis de Ibn Hayyān, véase M. Rius, «La actitud de los emires cordobeses hacia los astrólogos: entre la adicción y el rechazo», en Identidades marginales, C. de la Puente (ed.), Estudios Onomástico-Biográficos de al-Andalus, XIII, Madrid, 2003, 530-531.

${ }^{15}$ IQ, 1926: 89.

${ }^{16}$ IQ, 1926: 90.

${ }^{17}$ Lévi-Provençal, "España musulmana hasta la caída del Califato de Córdoba (711-1031 de J. C.), trad. E. García Gómez, en Historia de España de Ramón Menéndez Pidal, vol. IV, EspasaCalpe, Madrid, 1976, p. 214. 
${ }^{18}$ IQ, 1926: 91.

${ }^{19}$ IQ, 1926: 42-43.

${ }^{20} \mathrm{IQ}, 1926: 44$.

${ }^{21}$ Ahora bien, se dice que, a pesar del dolor y el miedo causado por este hombre a lo largo de su gobierno, tras el conflicto del Arrabal su salud se debilitó y que, según sus alfaquíes, sentía remordimientos por los crímenes cometidos. V. Lévi-Provençal, 1976: IV, 121-122. 